\title{
Assistive humanoid robot MARKO: development of the neck mechanism
}

\author{
Marko Penčić1, ${ }^{1}$, Maja C̆avić $^{1}$, Srđan Savić1, Milan Rackov ${ }^{1}$, Branislav Borovac ${ }^{1}$, and Zhenli \\ $\mathrm{Lu}^{2}$ \\ ${ }^{1}$ Faculty of Technical Sciences, University of Novi Sad, TrgDositejaObradovića 6, 21000 Novi Sad, Serbia \\ ${ }^{2}$ School of Electrical Engineering and Automation, Changshu Institute of Technology, Hushan Road 99, \\ 215500 Changshu, People's Republic of China
}

\begin{abstract}
The paper presents the development of neck mechanism for humanoid robots. The research was conducted within the project which is developing a humanoid robot Marko that represents assistive apparatus in the physical therapy for children with cerebral palsy.There are two basic ways for the neck realization of the robots. The first is based on low backlash mechanisms that have high stiffness and the second one based on the viscoelastic elements having variable flexibility. We suggest low backlash differential gear mechanism that requires small actuators. Based on the kinematic-dynamic requirements a dynamic model of the robots upper body is formed. Dynamic simulation for several positions of the robot was performed and the driving torques of neck mechanism are determined.Realized neck has 2 DOFs and enables movements in the direction of flexion-extension $100^{\circ}$, rotation $\pm 90^{\circ}$ and the combination of these two movements. It consists of a differential mechanism with three spiral bevel gears of which the two are driving and are identical, and the third one which is driven gear to which the robot head is attached. Power transmission and motion from the actuators to the input links of the differential mechanism is realized with two parallel placed gear mechanisms that are identical.Neck mechanism has high carrying capacity and reliability, high efficiency, low backlash that provide high positioning accuracy and repeatability of movements, compact design and small mass and dimensions.
\end{abstract}

\section{Introduction}

Children with non-progressive neuromuscular disorders, such as cerebral palsy [1], can have a significant deficit of motor functions and skills, body posture, as well as intellectual and emotional disorders [2]. The primary problem is a defect in the initiation and execution of the movement [3], considering that the motor activities represent the basis of human functioning.

The paper presents the development of neck mechanism for humanoid robots. The research was conducted within the project, which develops humanoid robot Marko that represents assistive apparatus in physical therapy for children with cerebral palsy - Fugure 1a. The

\footnotetext{
*Corresponding author: mpencic@uns.ac.rs
} 
conventional medical treatment involves exercises that are monotonous and exhausting for children, wherefore children lose interest for the work. Since the success of therapy depends directly on the time that child spent exercising, it is necessary to find a way to further motivate the child.The aim of the project is to offer the children a partner - robot, with which it will be more interesting for them to exercise and who will be able to demonstrate an exercise that the child cannot perform. It is expected are that the effects of the therapy will be increased through additional motivation and encouragement to the patient to exercise more. It should be noted that the robot is sitting the entire time on the mobile platform in the form of a horse and that the legs of the robot are intended solely for demonstration of movements during treatment, not for walking.

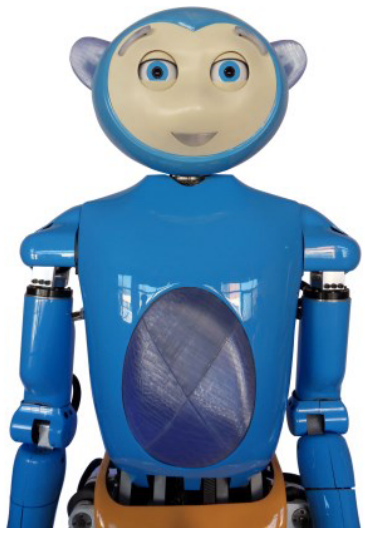

(a)

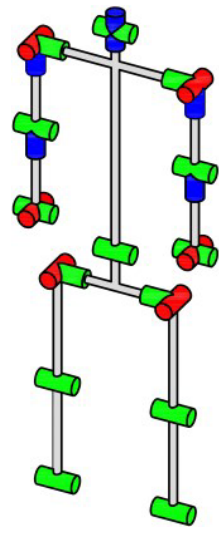

(b)

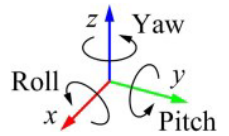

\begin{tabular}{lc}
\hline \multicolumn{1}{c}{ Joint } & DOF \\
\hline Eyebrows & 3 \\
Eyeballs & 4 \\
Eyelids & 4 \\
Neck & 2 \\
Arms & 14 \\
Hands* & 10 \\
Waist & 1 \\
Legs & 8 \\
\hline Total & 46 \\
\hline
\end{tabular}

Fig. 1. Photography of assistive humanoid robot Marko (a) and its kinematic structure (b).

Figure $2 \mathrm{~b}$ presents kinematic structure of the robot, which has a head with 11 DOFs, neck with 2 DOFs, two arms with 14 DOFs, two hands which should have 10 DOFs [4], waist with 1 DOF [5] and two legs with 8 DOFs [6], which makes the total 46 DOFs. In addition to verbal communication, Marko is able to intuitively realize nonverbal communication by moving the characteristic elements of the face - eyebrows, eyes, eyelids, and with the use of LEDs - ears and mouth are changing colors depending on the situational context of the robot.Therefore 3 DOFs eyebrows are realized, which is2 DOFs for the roll axis and 1 DOF for the yaw axis - lifting both eyebrows, 4 DOFs eyeballs, which is 2 DOFs for the yaw axis and 2 DOFs for the pitch axis, and 4 DOFs eyelids for the pitch axis -opening/closing the upper and lower eyelids.

\subsection{Human neck and its mobility}

Neck is multi-joint structure that connects the head to the chest. It is a part of the spine and consists of irregular bones that are placed one on top of the other and called vertebrae. The movements of the cervical spine are enabled with intervertebral joints and intervertebral discs that are placed between two adjacent vertebrae. Due to the elastic structure of disc, it is possible to perform locomotor activities of the neck and better amortization. In neck movements a large number of muscles and ligaments are involved. Neck provides stability and head posture, enableshead movements, transmits the load and absorbs shocks. Therefore, it has to be strong, stable and sufficiently movable. The movements between individual vertebrae are of small range, however, the mobility of the neck in whole is large, because it represents the sum of numerous small movements that are performed in 7 joints. 


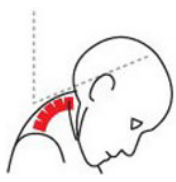

(a)

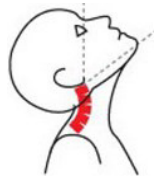

(b)

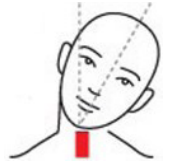

(c)

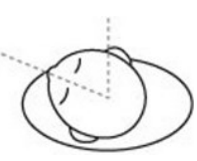

(d)

Fig. 2. The human neck movements: (a) bending forward - flexion, (b) bending backward - extension, (c) left/right side bending - lateral flexion and (d) left/right torsion - rotation.

In the cervical part of spinal column, there are movements flexion - bending forward (Fig. 2a), extension - bending backward (Fig. 2b), lateral flexion - side bending (Fig. 2c) and torsion - rotation (Fig. 2d). The mobility of the cervical spinefor the movement of flexionextension is approximately $100^{\circ}$. Head and neck movements are inseparable, so the overall mobility of the head and neck in the direction of flexion-extension is $130 \div 150^{\circ}$. Total lateral flexion movement of the neck is approximately $\pm 30^{\circ}$, and if the movement of the head is added, then the total lateral bending is approximately $\pm 50^{\circ}$. Rotation movements are approximately $\pm 80^{\circ}[7-9]$.

\section{State of the art}

There exist two basic groups of robots that can move the head independently from the trunk by activating the neck. The first group of robots has a neck with 2, 3 or 4 joints where each joint has 1 DOF - rigid structures, while the second group has a neck with 3-7 joints - spherical, spherical and rotational or universal and rotational, which is 9-19 DOFs - elastic structures.

Neck with 2 DOFs - movements about the yaw and pitch axes, have ASIMO [10], HUBO [11], HRP-4 [12], EveR1 [13], NAO [14], AILA [15], TORO [16], Justin [17], Pepper [18] etc.Neck with3 DOFs - movements about the yaw, roll and pitch axes, haveWABIAN-2 [19], Albert HUBO [20], HRP-4C [21], Affetto [22], iCub [23], Probo [24], EveR-2 [25], Geminoid F [26], Actroid-F [27] etc.Neck with4 DOFs - yaw, roll, upper and lower pitch movements, haveWE-4RII [28], ARMAR-III [29], ROMAN [30], KOBIAN [31], SAYA [32], BARTHOC [33], Romeo [34], Flutist Robot WF-4 [35], Twente Humanoid Head [36] etc.Neck structures with 2,3 or 4 DOFs usually consist of rigid and low backlash mechanisms that are interconnected - harmonic drive, cable-driven mechanisms, spindle drive, low backlash gears, etc. In addition to high reliability and carrying capacity, the advantage of these mechanisms is low backlash that provide high positioning accuracy and repeatability of movements.

Biologically inspired neck structures with 3-7 cervical vertebrae and large number of DOFs - movements about the yaw, pitch and roll axes, have Kenta [37], Kenji [38], Kotaro [39], Kojiro [40], Kenzoh [41], Kenshiro [42] and Kengoro [43].Each vertebra has points for attaching tendons which enables independent motion of each joint. Between each two vertebraethere isviscoelastic element - disc of silicone rubber and tension springs - ligaments. The height of each rubber disc is slightly greater than the distance between adjacent vertebrae and wherefore discs generate the pressure on the joints and ligaments tighten them.

During neck bending, the elastic elements generate force that opposes gravity and thereby help actuators.

The advantage of elastic elements is in achieving a significant force at the time of releasing the accumulated energy. In addition, flexible neck allows that the head movements are more natural and human-like. 


\section{Neck mechanism}

Since the robot head has the shape of an ellipsoid, the basic requirement is an adequate mobility of the head, respectively the neck about the pitch and yaw axes. In order to minimize driving torques it is necessary to decrease mass of the segments as much as possible. In addition the simple and reliable mechanisms are requiredthat have a high carrying capacity, high efficiency, low vibrations, low noise and low backlash that provide high positioning accuracy that enables high accuracy and repeatability of movements which is essential for motion control [44].

\subsection{Forces and torques}

The robot head is approximated by a sphere of mass $3.5 \mathrm{~kg}$ whose center of gravity is on distanceof $0.1 \mathrm{~m}$ above the neck joint. The neck movements should be as natural as possible and therefore it is adopted that their duration does not exceed $1 \mathrm{~s}$, which as a consequence have a certain dynamic effects. For that reason, based on the formed 3D model of the robot upper body a dynamic simulation was performed, and the driving torques of the neck mechanism are determined.

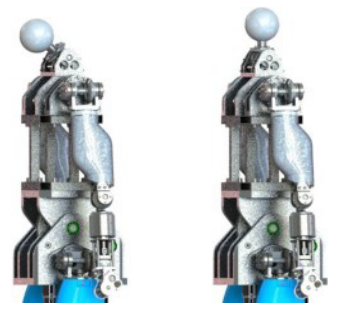

(a)

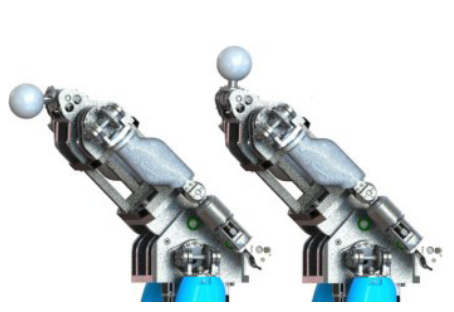

(b)

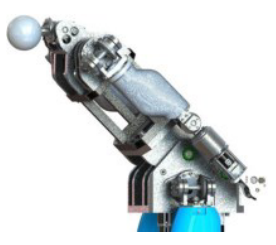

(c)

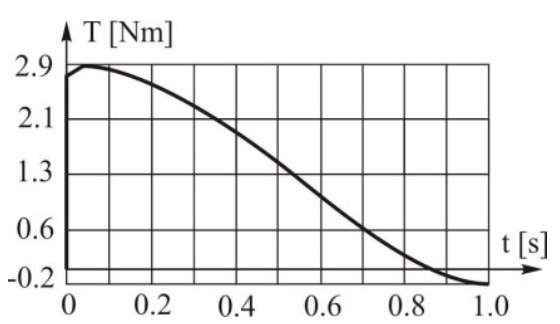

(d)

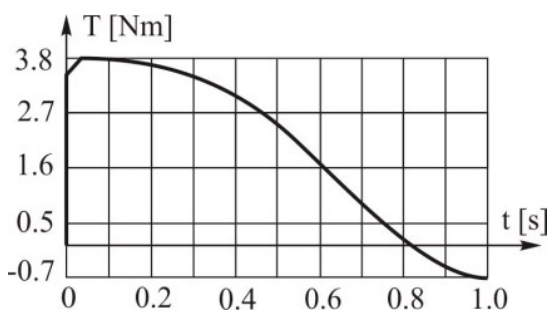

(e)

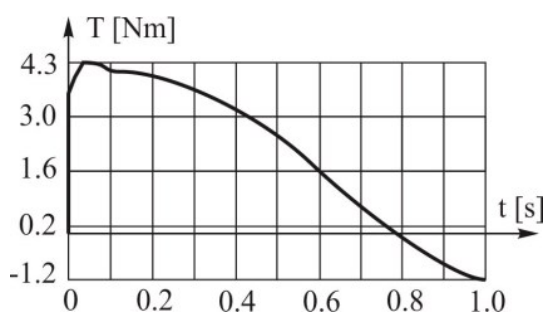

(f)

Fig. 3. Dynamic simulation of neck: (a) flexion of neck $-50^{\circ}$ to $0^{\circ}$, (b) flexion-extension of the neck $-50^{\circ}$ to $+50^{\circ}$ where the trunk is fixed in position of $-45^{\circ}$, (c) simultaneous movements of neck and trunk respectively flexion of the neck $-50^{\circ}$ to $0^{\circ}$ and flexion of the trunk $-45^{\circ}$ do $0^{\circ}$, and (d)-(e) graphics of torque changes for the appropriate range and movements of the neck mechanism. 
Three cases were examined depending on the type of movements and range of motion. The first is the neck flexion for range of motion from $-50^{\circ}$ to $0^{\circ}$ (Fig. 3a), the second is flexion-extension of the neck for range of motion from $-50^{\circ}$ to $+50^{\circ}$ where the trunk is fixed in position of $-45^{\circ}$ (Fig. 3b), while the third case involves the simultaneous flexion of neck and trunk in the range of $-50^{\circ}$ do $0^{\circ}$ for neck and $-45^{\circ}$ do $0^{\circ}$ for trunk(Fig. 3c).Profile of velocity is such that maximum values are reached in the middle of the movement - cubic polynomial trajectory. Based on the dynamic analysis the maximum torque value for dimensioning of the neck mechanism is $4.3 \mathrm{Nm}$.

\subsection{Mechanical design}

Realized neck has 2 DOFs and enables movements in the direction of flexion-extension $100^{\circ}$, rotation $\pm 90^{\circ}$, and the combination of these two movements. It is based on the differential mechanism with three bevel gears of which the first two are driving and are identical, and the third one which is the driven gear. If driving gears have the same circumferential velocity and the same direction of rotation, head moves about the pitch axis - flexion and extension of the neck - Figure $4 \mathrm{~b}$, and for the opposite direction of rotation, head moves about the yaw axis rotation of the neck - Figure 4c. If the circumferential velocities of driving gears are different a combination of these two movements is obtained - Figure $4 \mathrm{~d}$.

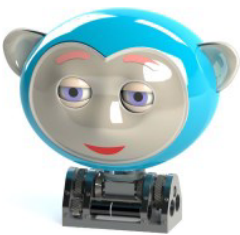

(a)

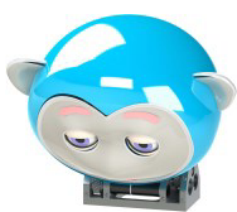

(b)

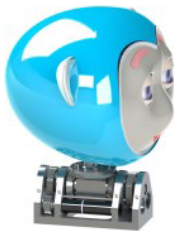

(c)

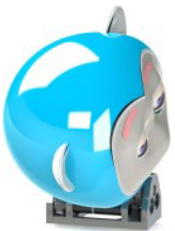

(d)

Fig. 4. The neck movements: (a) upright position, (b) flexion $50^{\circ}$, (c) left rotation $90^{\circ}$ and (d) flexion $50^{\circ}+$ left rotation $90^{\circ}$.

Figure 5 shows the structure of the neck mechanism. It consists of three subassembliestwo driving and identical, and one driven to which the robot head is attached. The driving subassembly consists of two support plates within which are placed the actuator and the elements for the power transmission and motion - bearings, shafts, helical gears and driving spiral bevel gear.

The actuator consists of a brushless DC motor, planetary gearhead with 3 stages and a magnetic encoder. Driving helical gear is directly attached on the gearhead shaft. Driven helical gear and driving bevel gear are placed on the same shaft - driving shaft. Driven subassembly has a housingwhich is used for mounting the two other subassemblies. Driven shaft, bearings and output links of the differential mechanism-driven bevel gear to which is attached the head support, are placed within the housing. Spiral bevel gears provide low backlash because several teeth are always in mesh. Low backlash at gearing with helical gears is achieved by precise machining of support plates and gears preloading - center distance is with negative tolerance.

Figure 6 shows a photograph of neck mechanism and in Table 1 its configuration is given. The neck width is $164 \mathrm{~mm}$, length $84 \mathrm{~mm}$, a height of $92 \mathrm{~mm}$, while the mass is $2 \mathrm{~kg}$. 


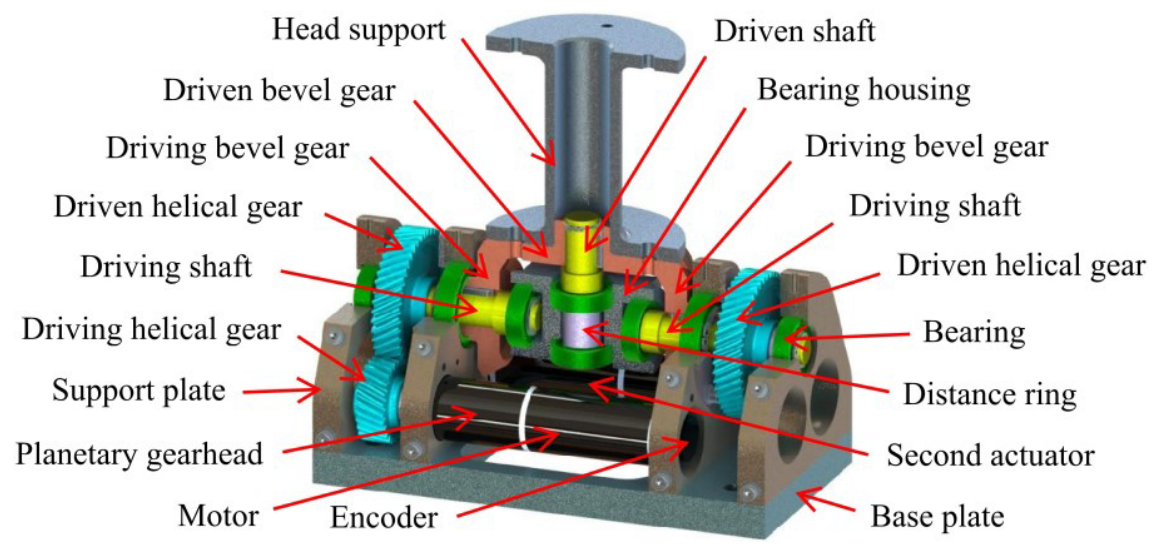

Fig. 5. Neck mechanismwith details - cross section.

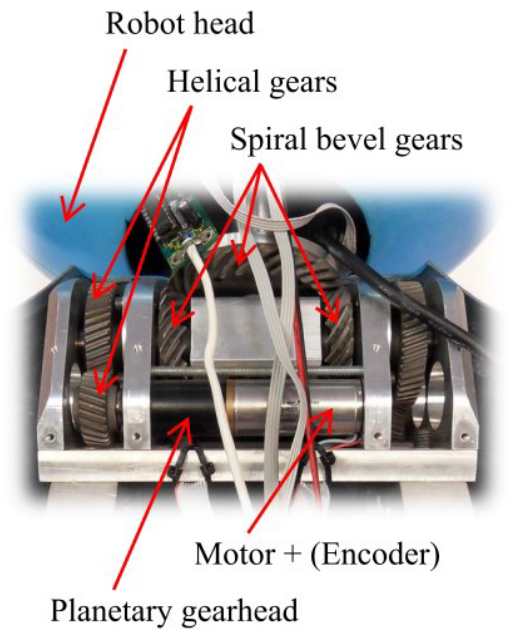

Fig. 6. Neck mechanism of the robot Marko.
Table 1. Neck mechanism configuration.

\begin{tabular}{|c|l|c|}
\hline Flexion-xtension and Rotation - neck joint \\
\hline \multirow{2}{*}{$\begin{array}{c}\text { Maxon motor } \\
\text { EC-max } 22 \\
(2 \text { pcs.) }\end{array}$} & Voltage [V] & 24 \\
\cline { 2 - 3 } & Power [W] & 25 \\
\cline { 2 - 3 } & Torque [mNm] & 22.7 \\
\cline { 2 - 3 } & Speed [rpm] & 10400 \\
\hline Planetary gearhead & Reduction & 157 \\
\cline { 2 - 3 } $\begin{array}{c}\text { GP 22-HP } \\
(2 \text { pcs.) }\end{array}$ & Torque [Nm] & 3 \\
\cline { 2 - 3 } Efficiency [\%] & 59 \\
\hline Encoder MR-ML & Channels & 3 \\
\cline { 2 - 3 }$(2$ pcs.) & Counts per turn & 512 \\
\hline $\begin{array}{c}\text { Gearing with } \\
\text { helical gears } \\
(2 \text { pcs.) }\end{array}$ & Reduction & 1.84 \\
\cline { 2 - 3 } & Module [mm] & 1 \\
\cline { 2 - 3 } $\begin{array}{c}\text { Gearing with } \\
\text { spiral bevel gears }\end{array}$ & Helix angle [ $\left.{ }^{\circ}\right]$ & 20 \\
\cline { 2 - 3 }$(2$ driving \&1 driven $)$ & Reduction & 1.625 \\
\cline { 2 - 3 } & Module [mm] & 1.5 \\
\hline
\end{tabular}

\section{Conclusion}

This paper presents the development of the neck mechanism for humanoid robots. Since the robot head has the shape of an ellipsoid, the basic requirement is to enable the mobility of the neck about the pitch and yaw axes. Based on the kinematic-dynamic requirements a dynamic model of the robots upper body is formed.

Dynamic simulation for several position of the robot is performed and the driving torques of neck mechanism are determined. Realized neck has 2 DOFs and enables movements in the direction of flexion-extension $100^{\circ}$, rotation $\pm 90^{\circ}$ and the combination of these two movements. It consists of a differential mechanism with three spiral bevel gears. First two are driving and identical, while the last one is driven gear to which the robot head is attached.

When driving gears have the same circumferential velocity and the same direction of rotation, head moves about the pitch axis - flexion and extension of the neck, and for the opposite direction head moves about the yaw axis - rotation of the neck. If the circumferential velocities of driving gears are different then a combination of these two movements is obtained. Power transmission and motion from the actuators to the input links of the differential mechanism is realized with two parallel placed gear mechanisms that are identical 
and consist of helical gears. Neck mechanism has high carrying capacity and reliability, high efficiency, compact design and low backlash that provides high positioning accuracy that enables high accuracy and repeatability of movements, which is essential for motion control.

This work was funded by the Ministry of Education and Science of the Republic of Serbia under the contract III 44008 and by the Provincial Secretariat for Science and Technological Development under the contract 114-451-2116/2011.

\section{References}

1. C. Bayon, R. Raya, S. Lerma-Lara, O. Ramirez, I. Serrano, E. Rocon, Transl. Biomed. 7(1), 1 (2016)

2. F. Miller, Physical Therapy of Cerebral Palsy, (Springer, New York, 2007)

3. I. Novak, S. McIntyre, C. Morgan, L. Campbell, L. Dark, N. Morton, E. Stumbles, S.A. Wilson, S. Goldsmith, Dev. Med. Child. Neurol. 55(1), 1 (2013)

4. S. Savić, M. Raković, M. Penčić, M. Nikolić, S. Dudić, B. Borovac, Proc. of the Int. Conf. on Electrical, Electronic and Computing Engineering - IcETRAN, Zlatibor, SR, (ROI1.4.) 1 (2016)

5. M. Penčić, M. Čavić, M. Rackov, B. Borovac, Proc. of theInter. Conf. on Accomp. in Mechanical and Industrial Engineering - DEMI, Banja Luka, BA, (to be published, 2017)

6. M. Penčić, S. Savić, M. Čavić, B. Borovac, Z. Lu, Proc. of theInt. Sci. and Expert Conf. - TEAM, Trnava, SK, 23 (2016)

7. M. Mijač, M. Blagotić, Lj. Djordjević, G. Teofilovski-Parapid, Humans Anatomy - Osteology (in Serbian), (Savremenaadministracija, Belgrade, 1998)

8. D. Nikolić, Kinesiology (in Serbian), (College of Health Studies, Ćuprija, 2007)

9. P. Opavsky, Introduction to Sports Biomechanics (in Serbian), (Author's edition, Belgrade, 1998)

10. Y. Sakagami, R. Watanabe, C. Aoyama, S. Matsunaga, N. Higaki, K. Fujimura, Proc. of the IEEE/RSJ Int. Conf. on Intelligent Robots and Systems, Lausanne, CH, , 32478 (2002)

11. I.-W. Park, J.-Y Kim, J. Lee, J.-H. Oh, Adv. Robot. 21(11) 1305 (2007)

12. K. Kaneko, F. Kanehiro, M. Morisawa, K. Akachi, G. Miyamori, A. Hayashi, N. Kanehira, Proc. of the IEEE/RSJ Int. Conf. on Intelligent Robots and Systems, San Francisco, CA, USA, 4400 (2011)

13. H.S. Ahn, D.-W. Lee, D. Choi, D.-Y. Lee, H.-G. Lee, M.-H. Baeg, Inter. J. Human. Robot. 10(2), $1350017(2013)$

14. D. Gouaillier, V. Hugel, P. Blazevic, C. Kilner, J. Monceaux, P. Lafourcade, B. Marnier, J. Serre, B. Maisonnier, Proc. of the IEEE-ICRA Int. Conf. on Robotics and Automation, Kobe, JP, 769 (2009)

15. J. Lemburg, J. de GeaFernández, M. Eich, D. Mronga, P. Kampmann, A. Vogt, A. Aggarwal, Y. Shi, F. Kirchner, Proc. of the IEEE-ICRA Int. Conf. on Robotics and Automation, Shanghai, CN, 5147 (2011)

16. J. Englsberger, A. Werner, C. Ott, B. Henze, M.A. Roa, G. Garofalo, R. Burger, A. Beyer, O. Eiberger, K. Schmid, A. Albu-Schäffer, Proc. of the IEEE-RAS Int. Conf. on Humanoid Robots, Madrid, ES, 916 (2014)

17. C. Ott, O. Eiberger, W. Friedl, B. Bauml, U. Hillenbrand, C. Borst, A. Albu-Schaffer, B. Brunner, H. Hirschmuller, S. Kielhofer, R. Konietschke, M. Suppa, T. Wimbock, F. Zacharias, G. Hirzinger, Proc. of the IEEE-RAS Int. Conf. on Humanoid Robots, Osaka, JP, 276 (2006)

18. J. Lafaye, D. Gouaillier, P. B. Wieber, Proc. of the IEEE-RAS Int. Conf. on Humanoid Robots, Madrid, ES, 336 (2014)

19. Y. Ogura, H. Aikawa, K. Shimomura, H. Kondo, A. Morishima, H.-O. Lim, A. Takanishi, Proc. of the IEEE-ICRA Int. Conf. on Robotics and Automation, Orlando, FL, USA, 76 (2006)

20. I.-W. Park, J.-Y Kim, B.-K. Cho, J.-H. Oh, Rob. Auton. Syst. 56(1), 95 (2008)

21. S. Kajita, K. Kaneko, F. Kaneiro, K. Harada, M. Morisawa, S. Nakaoka, K. Miura, K. Fujiwara, E.S. Neo, I. Hara, K. Yokoi, H. Hirukawa, Cybernetic Human HRP-4C: In book: C. Pradalier, R. Siegwart, and G. Hirzinger (eds.) Robotics Research: $14^{\text {th }}$ ISRR. STAR, 70, 301 (2011)

22. H. Ishihara, M. Asada, Adv. Robot. 29(18), 1151 (2015)

23. N.G. Tsagarakis, G. Metta, G. Sandini, D. Vernon, R. Beira, F. Becchi, L. Righetti, J. Santos-Victor, A.J. Ijspeert, M.C. Carrozza, D.G. Caldwell, Adv. Robot. 21(10), 1151 (2007)

24. K. Goris, J. Saldien, B. Vanderborght, D. Lefeber, Int. J. Hum. Robot. 8(3), 481 (2011)

25. H.S. Ahn, D.-W. Lee, D. Choi, D.Y Lee, M.H. Hur, H.Lee, W.H. Shon, Proc. of theAnnual Conf. of the IEEE-IECON Industrial Electronics Society, Melbourne, AU, 104 (2011) 
26. A. Becker-Asano, H. Ishiguro, Proc. of the IEEE-WACI Workshop on Affective Computational Intelligence, Paris, FR, 1 (2011)

27. M. Yoshikawa, Y. Matsumoto, M. Sumitani, H. Ishiguro, Proc. of the IEEE-ROBIO Int. Conf. on Robotics and Biomimetics, Phuket, TH, 2378 (2011)

28. K. Itoh, H. Miwa, M. Zecca, H. Takanobu, S. Roccella, M. C. Carrozza, P. Dario, A. Takanishi, In book: T. Zielinska, C. Zielinski (eds.) ROMANSY 16: Robot Design, Dynamics and Control. CISM, 487, 255 (2006)

29. T. Asfour, K. Regenstein, P. Azad, J. Schroder, A. Bierbaum, N. Vahrenkamp, R. Dillmann, Proc. of theIEEE-RAS Int. Conf. on Humanoid Robots, Genova, IT, 169 (2006)

30. N. Schmitz, J. Hirth, K. Berns, Proc. of theIEEE-RAS Int. Conf. on Hum. Robots, Daejeon, KR, 579 (2008)

31. M. Zecca, Y. Mizoguchi, K. Endo, F. Iida, Y. Kawabata, N. Endo, K. Itoh, A. Takanishi, Proc. of theIEEE-ROMAN Int. Symp. on Robot and Human Interactive Communication, Toyama, JP, 381 (2009)

32. T. Hashimoto, H. Kobayashi, N. Kato, Proc. of theIEEE-FUZZ Int. Conf. On Fuzzy Systems, Taipei, TW, 766 (2011)

33. M. Hackel, S. Schwope, J. Fritsch, B. Wrede, G. Sagerer, Proc. of theIEEE/RSJ Int. Conf. on Intelligent Robots and Systems, Edmonton, CA, 2443 (2005)

34. N. Pateromichelakis, A. Mazel, M. A. Hache, T. Koumpogiannis, R. Gelin, B. Maisonnier, A. Berthoz, Proc. of theIEEE/RSJ Int. Conf. on Intelligent Robots and Systems, Chicago, IL, USA, 1374 (2014)

35. K. Chida, I. Okuma, S. Isoda, Y. Saisu, K. Wakamatsu, K. Nishikawa, J. Solis, H. Takanobu, A. Takanishi, IEEE-ICRA Int. Conf. on Robotics and Automation, New Orleans, LA, USA, 1, 152 (2004)

36. R. Reilink, L. C. Visser, D.M. Brouwer, R. Carloni, S. Stramigioli, ISR 4(2), 107 (2011)

37. I. Mizuuchi, R. Tajima, T. Yoshikai, D. Sato, K. Nagashima, M. Inaba, Y. Kuniyoshi, H. Inoue, Proc. of the IEEE/RSJ Int. Conf. on Intelligent Robots and Systems, Lausanne, CH, 3, 2527 (2002)

38. I. Mizuuchi, T. Yoshikai, Y. Nakanishi, M. Inaba, Proc. of theIEEE/RSJ Int. Conf. on Int. Robots and Systems, Edmonton, CA, 692 (2005)

39. I. Mizuuchi, T. Yoshikai, Y. Sodeyama, Y. Nakanishi, A. Miyadera, T. Yamamoto, T. Niemela, M. Hayashi, J. Urata, Y. Namiki, T. Nishino, M. Inaba, Proc. of the IEEE-ICRA Int. Conf. on Robotics and Automation, Orlando, FL, USA, 82 (2006)

40. I. Mizuuchi, Y. Nakanishi, Y. Sodeyama, Y. Namiki, T. Nishino, N. Muramatsu, J. Urata, K. Hongo, T. Yoshikai, M. Inaba, Proc. of theIEEE-RAS Int. Conf. on Humanoid Robots, Pittsburgh, PA, USA, 294 (2007)

41. T. Izawa, M. Osada, N. Ito, S. Ohta, J. Urata, M. Inaba, Proc. of theIEEE-ROBIO Int. Conf. on Robotics and Biomimetics, Phuket, TH, 2384 (2011)

42. Y. Asano, T. Kozuki, H. Mizoguchi, Y. Motegi, M. Osada, T. Shirai, J. Urata, K. Okada, M. Inaba, Proc. of the IEEE-RAS Int. Conf. on Humanoid Robots, Osaka, JP, 811 (2012)

43. M. Kawamura, S. Ookubo, Y. Asano, T. Kozuki, K. Okada, M. Inaba, Proc. of theIEEE-RAS Int. Conf. on Humanoid Robots, Cancun, MX, 814 (2016)

44. M. Penčić, M. Čavić, B. Borovac, Proc. Of the Int. Conf. on Power Transmission - BAPT, Ohrid, MK, 115 (2016) 